\title{
Review
}

\section{Vestibular Rehabilitation after Vestibulopathy Focusing on the Application of Virtual Reality}

\author{
Masashi Matsumura ${ }^{1}$ and Toshihisa Murofushi ${ }^{2, *}$ \\ 1 Department of Physical Therapy, Faculty of Health Sciences, Kyorin University, 5-4-1 Mitaka-shi, \\ Tokyo 181-8612, Japan; matsumura@ks.kyorin-u.ac.jp \\ 2 Department of Otolaryngology, Teikyo University School of Medicine, Mizonokuchi Hospital, 5-1-1 Futago, \\ Takatsu-ku, Kawasaki 213-8507, Japan \\ * Correspondence: murofush@med.teikyo-u.ac.jp
}

Citation: Matsumura, M.; Murofushi,

T. Vestibular Rehabilitation after Vestibulopathy Focusing on the Application of Virtual Reality. J. Otorhinolaryngol. Hear. Balance Med. 2021, 2, 5. https://doi.org/10.3390/ ohbm 2020005

Academic Editor: Augusto

Pietro Casani

Received: 14 April 2021

Accepted: 13 May 2021

Published: 17 May 2021

Publisher's Note: MDPI stays neutral with regard to jurisdictional claims in published maps and institutional affiliations.

Copyright: (c) 2021 by the authors. Licensee MDPI, Basel, Switzerland. This article is an open access article distributed under the terms and conditions of the Creative Commons Attribution (CC BY) license (https:// creativecommons.org/licenses/by/ $4.0 /)$.

\begin{abstract}
Human postural control is regulated by the vestibular, somatosensory, and visual systems These types of sensory information are integrated in the central nervous system to ascertain the body's position in space. Proper functioning of the vestibular, somatosensory, and visual senses is necessary for the body to maintain equilibrium. Bilateral vestibulopathy (BVP) is a condition in which bilateral peripheral vestibular function is reduced. Its treatment includes vestibular rehabilitation (VeR), balance training, counseling, treating the underlying cause, and avoiding further damage to the vestibular system. As VeR is often tedious for patients, patient motivation is required or patients may drop out of the program. To solve this problem, in recent years, there have been increasing reports of VeR using virtual reality, which increases vestibulo-ocular reflex gain and decreased dizziness by inducing adaptation. In this review, we discuss VeR, particularly for BVP, and VeR using virtual reality.
\end{abstract}

Keywords: vestibular rehabilitation; bilateral vestibulopathy; virtual reality

\section{Introduction}

Patients with vestibular disorders have unpleasant symptoms, such as dizziness and instability. Vestibular rehabilitation (VeR) is a treatment method used to reduce these symptoms. A practice guideline on VeR for peripheral vestibular hypofunction was published by the American Physical Therapy Association in 2016 [1]. According to this guideline, both VeR for unilateral vestibulopathy (UVP) and bilateral vestibulopathy (BVP) are reported as Level of Evidence I and Recommendation A. Thus, the effectiveness of VeR has become well known. Here, we review VeR focusing on BVP and VeR using virtual reality (VR).

\section{Human Posture Control}

Human postural control is regulated by the vestibular, somatosensory, and visual systems [2-4]. The vestibular system has complexed functions. One of vestibular system functions is to detect misalignment between the vertical axis from the ground and the position of the head [5]. The vision system detects the position of the head from the information input from the eyes [5]. The somatosensory system detects the position of the leg from the support surface, where the foot is grounded. The somatosensory system also receives input from receptors in the joints, skin, and muscle tendons, including muscle spindles and Golgi tendon organs, and sends afferent signals to the central nervous system regarding changes in muscle length and tension [3]. These three types of sensory information are integrated in the central nervous system to ascertain the body's position in space and send motor commands to the musculoskeletal system to generate force in the appropriate direction. 
Proper functioning of the vestibular, somatosensory, and visual senses is necessary for the body to maintain equilibrium. Paterka reported that static standing posture during eye opening contributes to postural control at a rate of $17 \%$ for the vestibular, $50 \%$ for somatosensory, and $33 \%$ for visual, meanwhile, during eye closure, the rates are $0 \%$ for visual, $68 \%$ for somatosensory, and $32 \%$ for vestibular [4]. When vestibular information is reduced for any reason, somatosensory compensation and visual compensation occur [6]. If vestibular sensation is reduced and visual information is lost, we must rely on the somatosensory system. Therefore, postural control becomes difficult when somatosensory input is disturbed, especially on unstable floor surfaces [7].

\section{Vestibular Rehabilitation}

VeR was first reported in the 1940s by Cawthorn and Cooksey as exercise therapy for vertigo [8,9]. In the 1990s, Krebs conducted the first randomized controlled trial for BVP, which showed the effectiveness of VeR, although the sample size was small [10]. In 2015, a Cochrane review reported moderate to strong evidence that VeR for peripheral vestibular disorders was safe and effective [11]. In addition, a practice guideline on VeR for peripheral vestibular hypofunction was issued in 2016 [1].

The purposes of VeR include decreasing dizziness, increasing functional activity, and improving gaze stabilization, postural control, and quality of life (QOL) [12]. One of the strategies to achieve these purposes in VeR is vestibular compensation. However, vestibular compensation implies recovery from disequilibrium caused by unilateral vestibular dysfunction, and not recovery of impaired peripheral vestibular function itself [13]. It occurs through the plasticity in the central nervous system, compensating for dysfunction of the vestibular labyrinth and vestibular nerve on the affected side [13].

The types of VeR include gaze stabilization exercises, habituation exercises, substitution exercises, and balance training [2]. Gaze stability exercises are performed based on the concepts of adaptation and substitution to improve vestibulo-ocular reflex (VOR) gain [1]. VOR gain is reduced when vestibular hypofunction occurs, which in turn causes gaze instability [14]. Head movements promote the adaptation of vestibular function to improve gaze instability, resulting in reduction of dizziness $[12,15,16]$. The mechanism underlying this improvement is that error signals are generated by retinal slip during head movement and that this stimulus increases the VOR gain [16]. Gaze stability exercises include performing head movements in the vertical and horizontal directions while focusing on a hand-grasped or wall-mounted target. This facilitates adaptation of the vestibular system [1]. To induce greater adaptation of the VOR gain by this exercise, it is better to gradually increase the magnitude of the error signal due to retinal slip $[17,18]$. While it is important to not suddenly increase the difficulty level of the range and speed of head movements, it is more important to seek conditions that can be implemented according to the abilities of the patient. Difficulty can be increased by moving the hands and head in opposite directions $(\mathrm{VOR} \times 2)$ [16]. Herdman reported that gaze stability exercises in UVP and BVP improved dynamic visual acuity (DVA) in a dynamic environment $[19,20]$. It has also been reported that VeR for BVP, such as gaze stability exercises, walking exercises, and balance exercises, improved walking speed, and postural control [10].

Habituation exercises are performed to improve the symptoms induced by movement. Repetition of symptom-inducing movements reduces the magnitude of the response to repetitive sensory stimuli and decreases posture-induced dizziness [12,21]. Currently, optokinetic training is often used as habituation exercise [12]. An example of this is an exercise to familiarize oneself with an optokinetic drum-like pattern on a monitor. It is also possible to combine several elements, such as using a complex pattern for the background to perform gaze stability exercises.

Substitution exercise is a method of substituting the visual and somatosensory systems for the loss or impairment of the vestibular system. Typical methods include smoothpursuit eye movements or pre-programmed eye movements [1]. For example, during active eye-head exercise between targets, a large eye movement to a target is made before the 
head moves to face the target, potentially facilitating the use of preprogrammed eye movements [1]. It is also possible to encourage somatosensory and visual systems to predominate by altering sensory input using closed eyes and balance mats for postural control.

Balance training is performed in a variety of safety environments and situations by varying the base of support, support surface, and foot width [22]. There are methods for changing the center of gravity or shifting the weight. If balance training is to be performed at home, care should be taken to avoid falls. A physician or physiotherapist should check whether the patient can perform the exercise. Walking exercises should be set up and carried out in an appropriate indoor location after ascertaining whether the patient needs a walking aid such as a cane or needs someone's assistance.

$\mathrm{VeR}$ is more effective when exercises are tailored to the individual and performed under supervision than when performed unsupervised at home [23]. The difficulty of the exercises should be gradually increased and should be performed either through direct supervision of a physiotherapist through a guided home exercise program [23]. Patients are often reluctant to perform the exercises, so patient education is a priority [12].

\section{Bilateral Vestibulopathy}

BVP refers to a condition in which the bilateral peripheral vestibular function is reduced. It can either be idiopathic or with a clear etiology [24]. Baloh classified idiopathic BVP in to two types: progressive and sequential [25]. The prevalence of BVP in the United States was reported to be 28 per 100,000 people [26]. In a study of 255 BVPs in Germany, the mean age of men was $59.4 \pm 16.1$ years and the mean age of women was $65.9 \pm 14.7$ years [27]. The largest number of patients was reported to be in the $61-70$ years age group, followed by the 51-60 and 71-80 years age groups, with a wide distribution across all age groups, from young to old [27]. The most common cause of BVP with a clear etiology is the use of aminoglycoside antibiotics such as gentamicin and streptomycin, followed by Meniere's disease and meningitis [27]. The diagnostic criteria for BVP were published by the Barany Society in 2017 [28]. In 2019, diagnostic criteria for age-related mild bilateral vestibular hypofunction or presbyvestibulopathy were developed [29].

Patients with BVP has a higher risk of falling, with a 9-fold increase in fall risk among those with BVP in comparison to those with dizziness/imbalance but not BVP, and a 31-fold increase in fall risk in comparison to the nationwide average [26]. In addition, one-quarter of patients with BVP experience fall within 12 months [26]. Thus, BVP has balance impairments as one of its symptoms, which is a serious problem that can lead to falls. This may be due to the loss of vestibular input caused by BVP, which leads to the loss of function of the VOR and vestibulo-spinal reflex (VSR). Insufficient functioning of the VOR causes jumbling of the retinal image during fast head movements [28]. In addition, inadequate VSR leads to an inability to maintain balance during standing and walking, both of which worsen in darkness and on uneven ground [28]. The combination of peripheral neuropathy with bilateral peripheral vestibular disorders can cause abnormalities in gait rhythm (especially slow speed) and an increased risk of falling [30].

Vertigo disorders have been shown to provoke anxiety, panic disorders, and avoidance behavior [31]. Emotion, anxiety, and balance systems appear to share some common neural pathways [31,32]. This suggests that anxiety that occurs in BVP may be caused by factors other than the inner ear. Recent studies in humans with bilateral vestibular loss have shown that the hippocampus atrophies by $\sim 17 \%$ [33]. The hippocampus has also been linked to the control of anxiety [34]. Bilateral vestibular lesions cause atrophy of the hippocampus and subsequent deficits in spatial memory and the processing of emotional stimuli [35]. In addition, the vestibular nucleus receives substantial input from the Locus Coeruleus, Dorsal Raphe, and Parabrachial nuclei, which are also brain regions associated with mood disorders such as bipolar disorder [36-38]. Therefore, the vestibular system has been suggested as a potential window for exploring psychiatric symptomology $[36,38]$. Other symptoms such as limited social activities, concentration difficulties, and decreased quality of life have also been reported [39]. 
Two systematic reviews and one practice guideline have shown that physical therapy is effective for BVP $[1,39,40]$. Patients who develop BVP due to antibiotics, such as gentamicin, or anticancer drugs, such as cisplatin, experience limitations in daily living and social participation. Treatment of BVP includes VeR, balance training, counseling, interventions for the cause of BVP, and avoiding further damage to the vestibular labyrinth [41]. As for VeR for BVP, active head movements have been reported to be more effective than eye movements alone [42].

Symptoms caused by BVP may improve with physical therapy but at a lower rate of improvement than UVP [20,43]. Brown reported improvement rates of 33-55\% when VeR was performed in BVP [44]. Gillespie also reported that only $51 \%$ of subjects showed improvement, and $78 \%$ of whom developed BVP from ototoxic drugs [45]. On the other hand, Herdman reported $75-88 \%$ of improved cases with respect to multiple outcomes [46]. In a systematic review of BVP, there were moderate evidences for improvements in gaze stability and postural control [40]. However, there have been no reports of sufficient recovery of function currently.

\section{Virtual Reality (VR)}

VeR for BVP has been found to have certain effects. However, VeR is often tedious for patients, and further improvement is required. Therefore, it is often hard for patients to continue the program. Recently, there is an increase in reports of using virtual reality (VR) for VeR to address these issues.

VR is an interface between humans and computers that includes real-time simulation and interaction through various sensory channels, such as vision, sound, touch, smell, and taste [47]. VR is used in various fields, and in the medical field, it is used for anatomy, three-dimensional patient modeling, virtual surgery, and rehabilitation [47].

The neuroanatomical connection of the retina with the vestibular processing areas of the brain supports the usage of VR in VeR. The cortical (e.g., insular cortex) and subcortical (e.g., vestibular nuclei) vestibular brain regions are multisensory and respond to both visual and physical stimuli (head or body movement) [48]. Potentials generated by visual input to the retina are transmitted to brain regions associated with the vestibular system and may affect neural activity in the vestibular system, bringing about vestibular modulation [49].

Vection is important in understanding the mechanism of VR. Vection is defined as an illusory self-motion sensation in the absence of any head or body movement, experienced in a real or virtual world [50,51]. The dominant senses involved in the vection perception are vision and balance (vestibular) [52]. Vection along with other factors (e.g., eye movements) is usually accompanied with, and in most cases precedes, motion sickness (cybersickness in case of VR users) [50,53,54]. Cybersickness is a common consequence in VR. Cybersickness symptoms are caused when prolonged sensory inputs received from the visual and vestibular sensory trigger vection $[50,55]$. Vection does not necessarily induce cybersickness [52]. Factors such as sensory mismatch, visual flow, emotional state, and perceptual anticipation are involved when inducing vection is involved in the generation of vection and cybersickness [52].

The use of VR in the area of VeR was first reported in the 1990s by Viirre and Kramer [56,57]. Their study included the use of head-mounted displays (HMDs) and large screens [58-61]. To be more consistent in using VR may lead to increasing VOR gain and decreasing dizziness by inducing adaptation [62]. A summary of the intervention studies describe below can be shown in Table S1.

Some reports using screens are as follows. Rosiak implemented a "hybrid" VR procedure, combining motion trackers and force-plate platforms in patients with UVP, with significant improvement in posturographic parameters and subjective reduction of symptoms [63]. Gottshall found improvement in balance, gait, and visual function in young patients with vestibular disorders related to a recent mild traumatic brain injury when they used a treadmill and a large screen that moved with their gait [60]. Hondebrink performed VR VeR with a large screen. In patients with chronic UVP who are on wheelchairs, VR VeR 
brought significant improvement in dizziness handicap inventory (DHI) [61]. Sparrer used the Nintendo $\mathrm{Wii}^{\circledR}$ Balance Board in elderly patients with acute vestibular neuritis and found shorter hospitalization and improvements in DHI, sensory organization test, vertigo symptom scale, and Tinneti questionnaire than in the control group [64]. Yeh conducted virtual reality on a monitor with LED markers and 3D glasses for chronic balance disorders due to vestibular dysfunction [65]. They reported an improvement in balance ability and performance scores in VR games.

There are some reports of VeR using HMD. Micarelli found improvement in VOR, postural control, and QOL in UVP patients with mild cognitive impairment who employed VR at home using an HMD [58]. Park has shown that VR combined with HMD and eye trackers can improve goal-directed attention and activation of brain networks [59]. Hsu performed three-dimensional VR including eye and head movements in patients with Meniere's disease and reported that patients in the early stages of the disease or with mild functional disability had better balance than those in the chronic stage [66]. The use of VR in rehabilitation for patients diagnosed with unilateral or bilateral definite Ménière's disease showed improvement in DHI, dizziness visual analog scale, quality of life, and postural stability [67]. Viirre reported that active search tasks using HMD for patients who have chronic vertigo symptoms resulted in increased VOR gain [64]. Viziano investigated the long-term effects of VR using HMD in addition to VeR for UVP and found that the effects of VeR with VR were more sustained than those of conventional VeR [68]. In a randomized controlled trial conducted in 2017, a combination of VeR with HMD in patients with UVP showed improvement in VOR gain, posturography parameters, and DHI [69]. In implementing VR, given that time spent in VR is clearly of importance, longer sessions in a short period of time could be effective and convenient [70]. Ashiri measured vestibular responses during VR using a noninvasive method called Electrovestibulography (EVestG) [52]. The combined effects of the visually induced sensation of self-motion together with a concurrent-occurring stress anxiety factor can affect the vestibular activity in an excitatory way [52]. EVestG is used for post-concussion syndrome (PCS) and PCS shows a significant positive correlation between vestibular system abnormalities and convergence insufficiency [71]. EVestG is expected to be one of the methods to objectively evaluate vestibular function in the future.

A systematic review of VR conducted by Xie in 2021 suggests that there are more potential clinical benefits of $\mathrm{VR}$ for vestibular rehabilitation compared with conventional vestibular rehabilitation [72]. Using games in VR for VeR may lead patients to enjoy and immerse themselves in the rehabilitation process, which may also improve their motivation and ultimately lead them to continue VeR [47]. However, implementing VeR may require large-scale equipment or devices that are expensive. Therefore, further research is required to devise a method that can be used more broadly.

Matsumura reported a patient who underwent VeR using VR with successful outcomes [73]. Herein, we introduce this case. The patient, male, in his $50 \mathrm{~s}$, presented with severe disequilibrium, particularly in the dark. He was diagnosed with BVP due to gentamicin, which was used to treat endocarditis. Head movement induced dizziness in all directions, with yaw being more affected than pitch. The DHI score was 88 points $(\mathrm{P}=28$, $\mathrm{E}=30, \mathrm{~F}=30$ ). The VeR included gaze stability exercises, standing-up exercises, standing on one leg with the hand on the wall, and walking exercises around the house with his wife. The physiotherapist checked up on the patient once or twice a month. Approximately 1 year after the initial rehabilitation, rehabilitation using the simulator was initiated. Patients rode in an actual car at an indoor facility and drove a car using a racing simulator while watching the screen displayed on a large monitor that spanned 180 degrees in front of them. Although the steering wheel and accelerator were operated, the car did not actually move and no acceleration was applied; thus, visual and head movement stimuli were the main stimuli. After 10 sessions, stabilometry parameters were remarkably improved. He could play golf and go to the movies, activities he was not able to perform prior to. Even in a patient with BVP, VeR in combination with VR may be effective. 


\section{Discussion}

It has been shown that VeR is an effective treatment method supported by evidence. According to practice guideline, both VeR for UVP and BVP are reported as Level of Evidence I and Recommendation A [1]. BVP has balance impairments as one of its symptoms, which is a serious problem that can lead to falls. VeR has substantial effects on UVP, but limited effects on BVP. Treatment of BVP includes VeR, balance training, counseling, interventions for the cause of BVP, and avoiding further damage to the vestibular labyrinth.

One of the treatments for vestibular disorders has recently been the use of VR. The neuroanatomical connection of the retina with the vestibular processing areas of the brain supports the usage of VR in VeR. Patients who have vertigo can alter the neural activity of their vestibular system through sensory inputs from the visual system using VR. A systematic review suggests potential clinical benefit of VR for vestibular rehabilitation compared with conventional vestibular rehabilitation [72]. Most of the reports on the effects of VR are for UVP, but there is a report that it is also effective for BVP caused by Meniere's disease [66,67]. One of the adverse events of VR is cybersickness. It seems that a few patients suffer from cybersickness, which could be a subject for future studies.

Conventional VeR program is often tedious to patients. Therefore, patients often lose motivation, resulting in dropout. VeR is also limited by accessibility and time commitment. Recently, VR has been described as a VeR tool that may circumvent these barriers to treatment. Combining VeR with game elements, such as VR, is expected to increase the possibility of exercise continuity. VR in VeR is still in its development stage, but it has great potential. More research is expected in the future.

\section{Conclusions}

$\mathrm{VeR}$ is an effective treatment method supported by evidence. BVP has a serious balance problem that could lead to fall and perhaps to death. While VeR has clear benefits on UVP, it has limited ones on BVP. However, VR, which has been recently applied for $\mathrm{VeR}$, is a promising method. A systematic review suggests potential clinical benefits of it. Further clinical studies on VR in VeR are required.

Supplementary Materials: The following are available online at https:/ / www.mdpi.com/article/10 .3390/ohbm2020005/s1. Table S1: summary of the intervention studies.

Funding: This research received no external funding.

Conflicts of Interest: The authors declare no conflict of interest.

\section{References}

1. Hall, C.D.; Herdman, S.J.; Whitney, S.L.; Cass, S.P.; Clendaniel, R.A.; Fife, T.D.; Furman, J.M.; Getchius, T.S.; Goebel, J.A.; Shepard, N.T.; et al. Vestibular Rehabilitation for Peripheral Vestibular Hypofunction: An Evidence-Based Clinical Practice Guideline: FROM THE AMERICAN PHYSICAL THERAPY ASSOCIATION NEUROLOGY SECTION. J. Neurol. Phys. Ther. 2016, 40, 124-155. [CrossRef] [PubMed]

2. Horak, F.B.; Shupert, C.L.; Mirka, A. Components of postural dyscontrol in the elderly: A review. Neurobiol. Aging 1989, 10, 727-738. [CrossRef]

3. Gribble, P.A.; Hertel, J. Effect of lower-extremity muscle fatigue on postural control. Arch. Phys. Med. Rehabil. 2004, 85, 589-592. [CrossRef] [PubMed]

4. Peterka, R.J. Sensory integration for human balance control. Handb. Clin. Neurol. 2018, 159, 27-42. [PubMed]

5. Peterka, R.J. Sensorimotor integration in human postural control. J. Neurophysiol. 2002, 88, 1097-1118. [CrossRef] [PubMed]

6. Strupp, M.; Arbusow, V.; Dieterich, M.; Sautier, W.; Brandt, T. Perceptual and oculomotor effects of neck muscle vibration in vestibular neuritis. Ipsilateral somatosensory substitution of vestibular function. Brain 1998, 121, 677-685. [CrossRef]

7. Horak, F.B. Postural compensation for vestibular loss and implications for rehabilitation. Restor. Neurol. Neurosci. 2010, 28, 57-68. [CrossRef]

8. Cooksey, F. Rehabilitation in vestibular injuries. Proc. R. Soc. Med. 1946, 39, 273-278. [CrossRef]

9. Cawthorne, T. The physiological basis for head exercises. J. Chart. Soc. Physiother. 1944, 30, 106-107.

10. Krebs, D.E.; Gill-Body, K.M.; Riley, P.O.; Parker, S.W. Double-blind, placebo-controlled trial of rehabilitation for bilateral vestibular hypofunction: Preliminary report. Otolaryngol. Head Neck Surg. 1993, 109, 735-741. [CrossRef] 
11. McDonnell, M.N.; Hillier, S.L. Vestibular rehabilitation for unilateral peripheral vestibular dysfunction. Cochrane Database Syst. Rev. 2015, 1, CD005397. [CrossRef] [PubMed]

12. Whitney, S.L.; Alghwiri, A.A.; Alghadir, A. An overview of vestibular rehabilitation. Handb. Clin. Neurol. 2016, 137, 187-205.

13. Curthoys, I.S.; Halmagyi, G.M. Vestibular compensation. Adv. Otorhinolaryngol. 1999, 55, 82-110. [PubMed]

14. Herdman, S.J. Advances in the treatment of vestibular disorders. Phys. Ther. 1997, 77, 602-618. [CrossRef] [PubMed]

15. Horak, F.B.; Jones-Rycewicz, C.; Black, F.O.; Shumway-Cook, A. Effects of vestibular rehabilitation on dizziness and imbalance. Otolaryngol. Head Neck Surg. 1992, 106, 175-180. [CrossRef]

16. Herdman, S.J. Role of vestibular adaptation in vestibular rehabilitation. Otolaryngol. Head Neck Surg. 1998, 119, 49-54. [CrossRef]

17. Schubert, M.C.; Zee, D.S. Saccade and vestibular ocular motor adaptation. Restor. Neurol. Neurosci. 2010, 28, 9-18. [CrossRef]

18. Schubert, M.C.; Della Santina, C.C.; Shelhamer, M. Incremental angular vestibulo-ocular reflex adaptation to active head rotation. Exp. Brain Res. 2008, 191, 435-446. [CrossRef]

19. Herdman, S.J.; Hall, C.D.; Schubert, M.C.; Das, V.E.; Tusa, R.J. Recovery of dynamic visual acuity in bilateral vestibular hypofunction. Arch. Otolaryngol. Head Neck Surg. 2007, 133, 383-389. [CrossRef]

20. Herdman, S.J.; Schubert, M.C.; Das, V.E.; Tusa, R.J. Recovery of dynamic visual acuity in unilateral vestibular hypofunction. Arch. Otolaryngol. Head Neck Surg. 2003, 129, 819-824. [CrossRef]

21. Pavlou, M.; Lingeswaran, A.; Davies, R.A.; Gresty, M.A.; Bronstein, A.M. Simulator based rehabilitation in refractory dizziness. J. Neurol. 2004, 251, 983-995. [CrossRef]

22. Klatt, B.N.; Carender, W.J.; Lin, C.C.; Alsubaie, S.F.; Kinnaird, C.R.; Sienko, K.H.; Whitney, S.L. A Conceptual Framework for the Progression of Balance Exercises in Persons with Balance and Vestibular Disorders. Phys. Med. Rehabil. Int. $2015,2,1044$.

23. Eleftheriadou, A.; Skalidi, N.; Velegrakis, G.A. Vestibular rehabilitation strategies and factors that affect the outcome. Eur. Arch. Otorhinolaryngol. 2012, 269, 2309-2316. [CrossRef]

24. Lucieer, F.; Vonk, P.; Guinand, N.; Stokroos, R.; Kingma, H.; van de Berg, R. Bilateral Vestibular Hypofunction: Insights in Etiologies, Clinical Subtypes, and Diagnostics. Front. Neurol. 2016, 7, 26. [CrossRef]

25. Baloh, R.W.; Jacobson, K.; Honrubia, V. Idiopathic bilateral vestibulopathy. Neurology 1989, 39, 272-275. [CrossRef]

26. Ward, B.K.; Agrawal, Y.; Hoffman, H.J.; Carey, J.P.; Della Santina, C.C. Prevalence and impact of bilateral vestibular hypofunction: Results from the 2008 US National Health Interview Survey. JAMA Otolaryngol. Head Neck Surg. 2013, 139, 803-810. [CrossRef] [PubMed]

27. Zingler, V.C.; Cnyrim, C.; Jahn, K.; Weintz, E.; Fernbacher, J.; Frenzel, C.; Brandt, T.; Strupp, M. Causative factors and epidemiology of bilateral vestibulopathy in 255 patients. Ann. Neurol. 2007, 61, 524-532. [CrossRef]

28. Strupp, M.; Kim, J.S.; Murofushi, T.; Straumann, D.; Jen, J.C.; Rosengren, S.M.; Della Santina, C.C.; Kingma, H. Bilateral vestibulopathy: Diagnostic criteria Consensus document of the Classification Committee of the Bárány Society. J. Vestib. Res. 2017, 27, 177-189. [CrossRef] [PubMed]

29. Agrawal, Y.; Van de Berg, R.; Wuyts, F.; Walther, L.; Magnusson, M.; Oh, E.; Sharpe, M.; Strupp, M. Presbyvestibulopathy: Diagnostic criteria Consensus document of the classification committee of the Bárány Society. J. Vestib. Res. 2019, 29, 161-170. [CrossRef]

30. Schniepp, R.; Schlick, C.; Schenkel, F.; Pradhan, C.; Jahn, K.; Brandt, T.; Wuehr, M. Clinical and neurophysiological risk factors for falls in patients with bilateral vestibulopathy. J. Neurol. 2017, 264, 277-283. [CrossRef] [PubMed]

31. Balaban, C.D. Neural substrates linking balance control and anxiety. Physiol. Behav. 2002, 77, 469-475. [CrossRef]

32. Balaban, C.D.; Thayer, J.F. Neurological bases for balance-anxiety links. J. Anxiety Disord. 2001, 15, 53-79. [CrossRef]

33. Brandt, T.; Schautzer, F.; Hamilton, D.A.; Brüning, R.; Markowitsch, H.J.; Kalla, R.; Darlington, C.; Smith, P.; Strupp, M. Vestibular loss causes hippocampal atrophy and impaired spatial memory in humans. Brain 2005, 128 Pt 11, 2732-2741. [CrossRef]

34. Gray, J.A.; McNaughton, N. The neuropsychology of anxiety: Reprise. Nebr. Symp. Motiv. 1996, 43, 61-134. [PubMed]

35. Neo, P.; Carter, D.; Zheng, Y.; Smith, P.; Darlington, C.; McNaughton, N. Septal elicitation of hippocampal theta rhythm did not repair cognitive and emotional deficits resulting from vestibular lesions. Hippocampus 2012, 22, 1176-1187. [CrossRef] [PubMed]

36. Gurvich, C.; Maller, J.J.; Lithgow, B.; Haghgooie, S.; Kulkarni, J. Vestibular insights into cognition and psychiatry. Brain Res. 2013, 1537, 244-259. [CrossRef]

37. Balaban, C.D.; Jacob, R.G.; Furman, J.M. Neurologic bases for comorbidity of balance disorders, anxiety disorders and migraine: Neurotherapeutic implications. Expert Rev. Neurother. 2011, 11, 379-394. [CrossRef]

38. Lithgow, B.J.; Moussavi, Z.; Gurvich, C.; Kulkarni, J.; Maller, J.J. Fitzgerald PB. Bipolar disorder in the balance. Eur. Arch. Psychiatry Clin. Neurosci. 2019, 269, 761-775. [CrossRef]

39. Lucieer, F.; Duijn, S.; van Rompaey, V.; Pérez Fornos, A.; Guinand, N.; Guyot, J.P.; Kingma, H.; van de Berg, R. Full Spectrum of Reported Symptoms of Bilateral Vestibulopathy Needs Further Investigation-A Systematic Review. Front. Neurol. $2018,9,352$. [CrossRef]

40. Porciuncula, F.; Johnson, C.C.; Glickman, L.B. The effect of vestibular rehabilitation on adults with bilateral vestibular hypofunction: A systematic review. J. Vestib. Res. 2012, 22, 283-298. [CrossRef]

41. Strupp, M.; Feil, K.; Dieterich, M.; Brandt, T. Bilateral vestibulopathy. Handb. Clin. Neurol. 2016, 137, 235-240. [PubMed]

42. Lehnen, N.; Kellerer, S.; Knorr, A.G.; Schlick, C.; Jahn, K.; Schneider, E.; Heuberger, M.; Ramaioli, C. Head-Movement-Emphasized Rehabilitation in Bilateral Vestibulopathy. Front. Neurol. 2018, 9, 562. [CrossRef] 
43. Herdman, S.J.; Hall, C.D.; Maloney, B.; Knight, S.; Ebert, M.; Lowe, J. Variables associated with outcome in patients with bilateral vestibular hypofunction: Preliminary study. J. Vestib. Res. 2015, 25, 185-194. [CrossRef] [PubMed]

44. Brown, K.E.; Whitney, S.L.; Wrisley, D.M.; Furman, J.M. Physical therapy outcomes for persons with bilateral vestibular loss. Laryngoscope 2001, 111, 1812-1817. [CrossRef]

45. Gillespie, M.B.; Minor, L.B. Prognosis in bilateral vestibular hypofunction. Laryngoscope 1999, 109, 35-41. [CrossRef] [PubMed]

46. Herdman, S.J.; Hall, C.D.; Delaune, W. Variables associated with outcome in patients with unilateral vestibular hypofunction. Neurorehabil. Neural. Repair. 2012, 26, 151-162. [CrossRef]

47. Song, J.J. Virtual Reality for Vestibular Rehabilitation. Clin. Exp. Otorhinolaryngol. 2019, 12, 329-330. [CrossRef] [PubMed]

48. Ashiri, M.; Lithgow, B.; Suleiman, A.; Blakley, B.; Mansouri, B.; Moussavi, Z. Differences Between Physical vs. Virtual Evoked Vestibular Responses. Ann. Biomed. Eng. 2020, 48, 1241-1255. [CrossRef]

49. Ashiri, M.; Lithgow, B.; Mansouri, B.; Moussavi, Z. Comparison between vestibular responses to a physical and virtual reality rotating chair. In Proceedings of the 11th Augmented Human International Conference, Winnipeg, MB, Canada, 27-29 May 2020; Volume 16, pp. 1-4.

50. Keshavarz, B.; Riecke, B.E.; Hettinger, L.J.; Campos, J.L. Vection and visually induced motion sickness: How are they related? Front. Psychol. 2015, 6, 472. [CrossRef] [PubMed]

51. Palmisano, S.; Allison, R.S.; Schira, M.M.; Barry, R.J. Future challenges for vection research: Definitions, functional significance, measures, and neural bases. Front. Psychol. 2015, 6, 193. [CrossRef]

52. Ashiri, M.; Lithgow, B.; Suleiman, A.; Mansouri, B.; Moussavi, Z. Quantitative measures of the visually evoked sensation of body movement in space (Vection) using Electrovestibulography (EVestG). Virtual Real. 2020. [CrossRef]

53. Hettinger, L.J.; Berbaum, K.S.; Kennedy, R.S.; Dunlap, W.P.; Nolan, M.D. Vection and simulator sickness. Mil. Psychol. 1990, 2, 171-181. [CrossRef] [PubMed]

54. Smart, L.J., Jr.; Stoffregen, T.A.; Bardy, B.G. Visually induced motion sickness predicted by postural instability. Hum. Factors 2002, 44, 451-465. [CrossRef]

55. Dieterich, M.; Bense, S.; Stephan, T.; Yousry, T.A.; Brandt, T. fMRI signal increases and decreases in cortical areas during small-field optokinetic stimulation and central fixation. Exp. Brain Res. 2003, 148, 117-127. [CrossRef] [PubMed]

56. Viirre, E. Vestibular telemedicine and rehabilitation. Applications for virtual reality. Stud. Health Technol. Inform. 1996, 29, 299-305.

57. Kramer, P.D.; Roberts, D.C.; Shelhamer, M.; Zee, D.S. A versatile stereoscopic visual display system for vestibular and oculomotor research. J. Vestib. Res. 1998, 8, 363-379. [CrossRef]

58. Micarelli, A.; Viziano, A.; Micarelli, B.; Augimeri, I.; Alessandrini, M. Vestibular rehabilitation in older adults with and without mild cognitive impairment: Effects of virtual reality using a head-mounted display. Arch. Gerontol. Geriatr. 2019, 83, 246-256. [CrossRef]

59. Park, J.H.; Jeon, H.J.; Lim, E.C.; Koo, J.W.; Lee, H.J.; Kim, H.J.; Lee, J.S.; Song, C.G.; Hong, S.K. Feasibility of Eye Tracking Assisted Vestibular Rehabilitation Strategy Using Immersive Virtual Reality. Clin. Exp. Otorhinolaryngol. 2019, 12, 376-384. [CrossRef]

60. Gottshall, K.R.; Sessoms, P.H.; Bartlett, J.L. Vestibular physical therapy intervention: Utilizing a computer assisted rehabilitation environment in lieu of traditional physical therapy. Annu. Int. Conf. IEEE Eng. Med. Biol. Soc. 2012, 2012, 6141-6144.

61. Hondebrink, M.S.; Mert, A.; van der Lint, R.; de Ru, J.A.; van der Wurff, P. Motion-based equilibrium reprocessing therapy a novel treatment method for chronic peripheral vestibulopathies: A pilot study. Medicine 2017, 96, e7128. [CrossRef]

62. Viirre, E.; Sitarz, R. Vestibular rehabilitation using visual displays: Preliminary study. Laryngoscope 2002, 112, 500-503. [CrossRef] [PubMed]

63. Rosiak, O.; Krajewski, K.; Woszczak, M.; Jozefowicz-Korczynska, M. Evaluation of the effectiveness of a Virtual Reality-based exercise program for Unilateral Peripheral Vestibular Deficit. J. Vestib. Res. 2018, 28, 409-415. [CrossRef] [PubMed]

64. Sparrer, I.; Duong Dinh, T.A.; Ilgner, J.; Westhofen, M. Vestibular rehabilitation using the Nintendo ${ }^{\circledR}$ Wii Balance Board-A user-friendly alternative for central nervous compensation. Acta Otolaryngol. 2013, 133, 239-245. [CrossRef] [PubMed]

65. Yeh, S.C.; Chen, S.; Wang, P.C.; Su, M.C.; Chang, C.H.; Tsai, P.Y. Interactive 3-dimensional virtual reality rehabilitation for patients with chronic imbalance and vestibular dysfunction. Technol. Health Care 2014, 22, 915-921. [CrossRef] [PubMed]

66. Hsu, S.Y.; Fang, T.Y.; Yeh, S.C.; Su, M.C.; Wang, P.C.; Wang, V.Y. Three-dimensional, virtual reality vestibular rehabilitation for chronic imbalance problem caused by Ménière's disease: A pilot study. Disabil. Rehabil. 2017, 39, 1601-1606. [CrossRef] [PubMed]

67. Garcia, A.P.; Ganança, M.M.; Cusin, F.S.; Tomaz, A.; Ganança, F.F.; Caovilla, H.H. Vestibular rehabilitation with virtual reality in Ménière's disease. Braz. J. Otorhinolaryngol. 2013, 79, 366-374. [CrossRef] [PubMed]

68. Viziano, A.; Micarelli, A.; Augimeri, I.; Micarelli, D.; Alessandrini, M. Long-term effects of vestibular rehabilitation and headmounted gaming task procedure in unilateral vestibular hypofunction: A 12-month follow-up of a randomized controlled trial. Clin. Rehabil. 2019, 33, 24-33. [CrossRef] [PubMed]

69. Micarelli, A.; Viziano, A.; Augimeri, I.; Micarelli, D.; Alessandrini, M. Three-dimensional head-mounted gaming task procedure maximizes effects of vestibular rehabilitation in unilateral vestibular hypofunction: A randomized controlled pilot trial. Int. J. Rehabil. Res. 2017, 40, 325-332. [CrossRef]

70. Bergeron, M.; Lortie, C.L.; Guitton, M.J. Use of Virtual Reality Tools for Vestibular Disorders Rehabilitation: A Comprehensive Analysis. Adv. Med. 2015, 2015, 916735. [CrossRef]

71. Suleiman, A.; Lithgow, B.J.; Anssari, N.; Ashiri, M.; Moussavi, Z.; Mansouri, B. Correlation between Ocular and Vestibular Abnormalities and Convergence Insufficiency in Post-Concussion Syndrome. Neuroophthalmology 2020, 44, 157-167. [CrossRef] 
72. Xie, M.; Zhou, K.; Patro, N.; Chan, T.; Levin, M.; Gupta, M.K.; Archibald, J. Virtual Reality for Vestibular Rehabilitation: A Systematic Review. Otol. Neurotol. 2021. online ahead of print. [CrossRef] [PubMed]

73. Matsumura, M.; Murofushi, T. Vestibular rehabilitation to bilateral vestibulopathy. Equilib. Res. 2021, in press. 